\title{
Postarthroscopy Imaging in Femoroacetabular Impingement: Persistent Pain May Be Due to an Insufficient Correction of Preoperative Abnormalities
}

\author{
Cosimo Tudisco ${ }^{1}$ Salvatore Bisicchia ${ }^{1}$ Sandro Tormenta ${ }^{2}$ Amedeo Taglieri ${ }^{3}$ Ezio Fanucci ${ }^{2}$
}

${ }^{1}$ Department of Orthopaedic Surgery, University of Rome Tor Vergata, Rome, Italy

2 Department of Radiology, San Pietro Fatebenefratelli Hospital, Rome, Italy

3 Department of Diagnostic Imaging, Molecular Imaging, Interventional Radiology and Radiation Therapy, University of Rome Tor Vergata, Rome, Italy

Joints 2017;5:21-26.
Address for correspondence Cosimo Tudisco, MD, Department of Orthopaedic Surgery, University of Rome Tor Vergata, Viale Oxford 81, 00133, Rome, Italy (e-mail: cosimo.tudisco@uniroma2.it).

\begin{abstract}
Keywords

- femoroacetabular impingement

- hip arthroscopy

- magnetic resonance imaging

- hip pain

Purpose The purpose of this study was to evaluate the effect of correction of abnormal radiographic parameters on postoperative pain in a group of patients treated arthroscopically for femoracetabular impingement (FAI).

Methods A retrospective study was performed on 23 patients affected by mixed-type FAl and treated arthroscopically. There were 11 males and 12 females with a mean age of 46.5 (range: 28-67) years. Center-edge (CE) and $\alpha$ angles were measured on preoperative and postoperative radiographic and magnetic resonance imaging (MRI) studies and were correlated with persistent pain at follow-up.

Results The mean preoperative CE and $\alpha$ angles were $38.6 \pm 5.2$ and $67.3 \pm 7.2$ degrees, respectively. At follow-up, in the 17 pain-free patients, the mean pre- and postoperative $C E$ angle were $38.1 \pm 5.6$ and $32.6 \pm 4.8$ degrees, respectively, whereas the mean pre- and postoperative $\alpha$ angles at MRI were $66.3 \pm 7.9$ and $47.9 \pm 8.9$ degrees, respectively. In six patients with persistent hip pain, the mean pre- and postoperative $C E$ angles were $39.8 \pm 3.6$ and $35.8 \pm 3.1$ degrees, respectively, whereas the mean pre- and postoperative $\alpha$ angles were $70.0 \pm 3.9$ and $58.8 \pm 2.6$ degrees, respectively. Mean values of all the analyzed radiological parameters, except CE angle in patients with pain, improved significantly after surgery. On comparing patient groups, significantly lower postoperative $\alpha$ angles and lower CE angle were observed in patients without pain.

Conclusion In case of persistent pain after arthroscopic treatment of FAI, a new set of imaging studies must be performed because pain may be related to an insufficient correction of preoperative radiographic abnormalities.

Level of Evidence Level IV, retrospective case series.
\end{abstract}

DOI http://dx.doi.org/ $10.1055 / \mathrm{s}-0037-1601411$. ISSN 2282-4324.
Copyright @ 2017 Georg Thieme Verlag KG Stuttgart · New York
License terms

(c) (1) $\odot \circledast$ 


\section{Introduction}

Femoroacetabular impingement (FAI) is a common cause of groin pain in active young and middle-aged patients resulting from abutment between proximal femur and acetabulum. This disorder can be functional or can result from anatomical abnormalities on either the femoral head-neck (cam-type) or acetabulum (pincer-type), or often a combination (mixed-type). ${ }^{1-3}$

Operative treatment is often indicated to answer the functional requests of these patients. Surgery is aimed at reducing pincer lesions, increasing femoral head-neck offset (osteochondroplasty), and treating associated soft tissue lesions such as labral tears. Recently, arthroscopic procedures have become increasingly popular for the treatment of FAI. ${ }^{4-6}$ However, not all patients improve after surgery, and persistent bone impingement has been reported as the most frequent cause for revision. ${ }^{7-9}$ Although several criteria have been proposed in the preoperative setting, ${ }^{4}$ the postsurgical imaging of FAI has been sporadically discussed in the literature. $^{9-16}$

The purpose of this study was to retrospectively evaluate the preoperative and postoperative radiographic and magnetic resonance imaging (MRI) findings in a group of patients treated arthroscopically for FAI, with particular reference to pain. Our hypothesis was that patients with persistent hip pain after surgery had an insufficient correction of preoperative radiographic abnormalities.

\section{Methods}

This study was approved by the local ethic committee and was performed in accordance with the ethical standards of the 1964 Declaration of Helsinki as revised in 2000. The ethic committee waived the need for informed consent for publication since rights and interests of the patients would not be violated and their privacy and anonymity would be assured by this study design.
From a pool of 42 patients undergoing hip arthroscopy, we retrospectively selected 25 patients treated for a mixed-type FAI according to inclusion and exclusion criteria listed in -Table 1. ${ }^{17-24}$ Among these, 23 patients (23 hips) were available for follow-up evaluation. There were 11 male and 12 female, with an average age of 46.5 (range: 28-67) years. Radiographs and MRIs were performed preoperatively and at a mean of $6.0 \pm 1.5$ months postoperatively, with the same scanner and standard techniques.

Radiographs included a well-centered anteroposterior (AP) standing pelvis view, unilateral AP view, and crosstable lateral view of the hip. ${ }^{25}$ Because magnetic resonance arthrography (MR-A) may inaccurately diagnose the presence of persistent, recurrent, or unhealed labral tears after surgery, ${ }^{26}$ standard MRI was performed in all cases using a 1.5-Tesla MR unit (Achieva, General Electric, Milwaukee, Wisconsin, United States). A flexible, wrap-around, receiveonly surface coil was used. Coronal T1-weighted fast spinecho sequence and STIR (short tau inversion recovery) sequence, sagittal T1-weighted fast spin-echo sequence and axial proton density (PD)-weighted fast spin-echo sequence with fat saturation were performed; a transverse oblique (parallel to the long axis of the femoral neck) PD- or T1-weighted fast spin-echo sequences were also performed.

Hip arthroscopies were performed in the lateral position and under general anesthesia. Three portals (anterolateral, posterior paratrochanteric, and superior) were commonly used, with further portals being added if required. Cam-type impingement lesions were excised with arthroscopic burr (osteochondroplasty); pincer-type impingement lesions were treated by partial detachment of the labrum, acetabuloplasty, and labrum suture with anchors; loose bodies were removed and other intra-articular procedures were performed as needed. Osteochondroplasty was judged adequate when by dynamic examination and with direct visualization, an impingement-free internal rotation of at least 30 degrees in the 90-degree flexed hip position was achieved. After

Table 1 Inclusion and exclusion criteria

\begin{tabular}{|l|l|}
\hline Inclusion criteria & Exclusion criteria \\
\hline Positive impingement sign ${ }^{15}$ & Previous surgery on the same hip \\
\hline Limited internal rotation of the hip of $\sim 20$ degrees, at 90 degrees of flexion & $\begin{array}{l}\text { Acetabular retroversion with insufficient } \\
\text { posterior wall (positive posterior wall } \\
\text { sign })^{17} \text { on X-rays }\end{array}$ \\
\hline Cam deformity ( $\alpha$ angle $>55$ degrees) on axial MRI scans ${ }^{16}$ & CE angle $<20$ degrees $^{21}$ \\
\hline $\begin{array}{l}\text { Pincer deformity (crossover sign, }{ }^{17} \text { coxa profunda, }{ }^{18} \text { or protrusio acetabuli }{ }^{19} \text { ) } \\
\text { on anteroposterior pelvic X-rays) }\end{array}$ & $\begin{array}{l}\text { Sequels of childhood hip disease, such as } \\
\text { Perthes' disease or slipped capital femoral } \\
\text { epiphysis }\end{array}$ \\
\hline $\begin{array}{l}\text { Chondrolabral lesions on MRI scans } \\
\text { Loose bodies }\end{array}$ & $\begin{array}{l}\text { Hip osteoarthritis }>\text { grade } 1 \text { according to } \\
\text { the Tönnis classification }\end{array}$ \\
\hline $\begin{array}{l}\text { No more than } 6 \text { mo of failed conservative treatment } \\
\text { (rest, activity restriction, NSAIDs) before surgery }\end{array}$ & Previous infection on the same hip \\
\hline Written informed consent & $\begin{array}{l}\text { Autoimmune diseases (i.e., rheumatoid } \\
\text { arthritis) }\end{array}$ \\
\hline
\end{tabular}

Abbreviations: CE, center-edge; MRI, magnetic resonance imaging; NSAIDs, nonsteroidal anti-inflammatory drugs. 
surgery, weight-bearing as tolerated on two crutches for 6 weeks was prescribed.

The same well-trained musculoskeletal radiologist, who was unaware of the clinical results, measured in a blinded fashion preoperative and postoperative center-edge (CE) angle $^{23}$ on AP view of the pelvis and $\alpha$ angle ${ }^{18}$ on axial MRI scans. Alpha angles were measured on MRI because on plain radiographs, the asphericity of the femoral head would be underestimated. ${ }^{25,27-32}$

Descriptive statistics were used to summarize the characteristics of the study group and subgroups, including mean and standard deviation of all continuous variables. An unpaired two-sided Student's $t$-test was used to compare objective outcomes. Significance was defined as $p<0.05$. Statistical analyses were performed with SPSS v.15.0 (IBM, Chicago, Illinois, United States).

\section{Results}

For the whole group of patients, the mean preoperative CE angle at radiographic evaluation was $38.6 \pm 5.2$ degrees, whereas on MRI scans, the mean preoperative $\alpha$ angle was $67.3 \pm 7.2$ degrees. Preoperative MRI also revealed that 20 of 23 hips had a cartilage abnormality that involved the anterosuperior acetabulum. One patient had an anterosuperior cartilage defect at surgery that was not visible at imaging. Twenty-one hips had an anterosuperior labral tear.

At follow-up, 17 patients were pain-free, and imaging studies documented no pathological bone, chondral, or labral finding. In this group of patients, the mean preoperative and postoperative CE angles were $38.1 \pm 5.6$ and $32.6 \pm 4.8$ degrees, respectively ( - Fig. 1), whereas the mean preoperative and postoperative $\alpha$ angle on MRI scans were $66.3 \pm 7.9$ and $47.9 \pm 8.9$ degrees, respectively (-Fig. 2 ).

Among the six patients with persistent hip pain at followup, MRI evidenced persistence of bone edema and signs of acetabular labrectomy (labral borders irregularity with persistent fragmentation and chronic synovial flogosis) in four cases. In the two remaining cases in which FAI was associated to loose bodies, a reduction in their number was found without persistent edema associated to acetabular labrectomy. In this group of patients with persistent hip pain, the mean preoperative and postoperative $\mathrm{CE}$ angles were $39.8 \pm 3.6$ and $35.8 \pm 3.1$ degrees, respectively (-Fig. 3 ), whereas the mean preoperative and postoperative $\alpha$ angles were $70.0 \pm 3.9$ and $58.8 \pm 2.6$ degrees, respectively (-Fig. 4).

On comparing patients with and without persistent hip pain after arthroscopy, we did not observe any significant difference in terms of gender, age, and preoperative CE and $\alpha$ angles. Mean values of the analyzed radiological parameters improved significantly after surgery, except mean CE angle in patients with residual hip pain $(p=0.1)$. Patients without pain showed significantly lower postoperative $\alpha$ angle $(p=0.008)$ and lower CE angle $(p=0.07)$ than those with residual pain.

\section{Discussion}

Imaging after surgical treatment of FAI is demanding due to controversies in the selection of the appropriate diagnostic protocol and in the differentiation between normal and pathological findings. Direct MR-A is considered the gold standard in the preoperative setting; however, it is unable to accurately diagnose the presence of persistent, recurrent, or unhealed labral tears after surgery. ${ }^{26}$ Furthermore, MR-A requires fluoroscopic or sonographic guidance for the intraarticular injection of the contrast medium, has a potential risk of infection, and is not always well accepted by the patients. ${ }^{33}$ Conventional MRI may be used, but the imaging protocol is not widely reproducible in the average clinical setting. $^{34,35}$

On plain radiographs, $\alpha$ angle values higher than 50 to 55 degrees have been commonly used as a two-dimensional threshold indicating cam-type impingement. ${ }^{18,27,36}$ However, the values of this angle have been demonstrated to vary between radiographic views, leading to unreliability in the clinical practice. ${ }^{37}$ MRI has been used to analyze the three-dimensional $\alpha$ angles, aiming to a better evaluation of the sphericity of the femoral head, ${ }^{25,27-32}$ but some
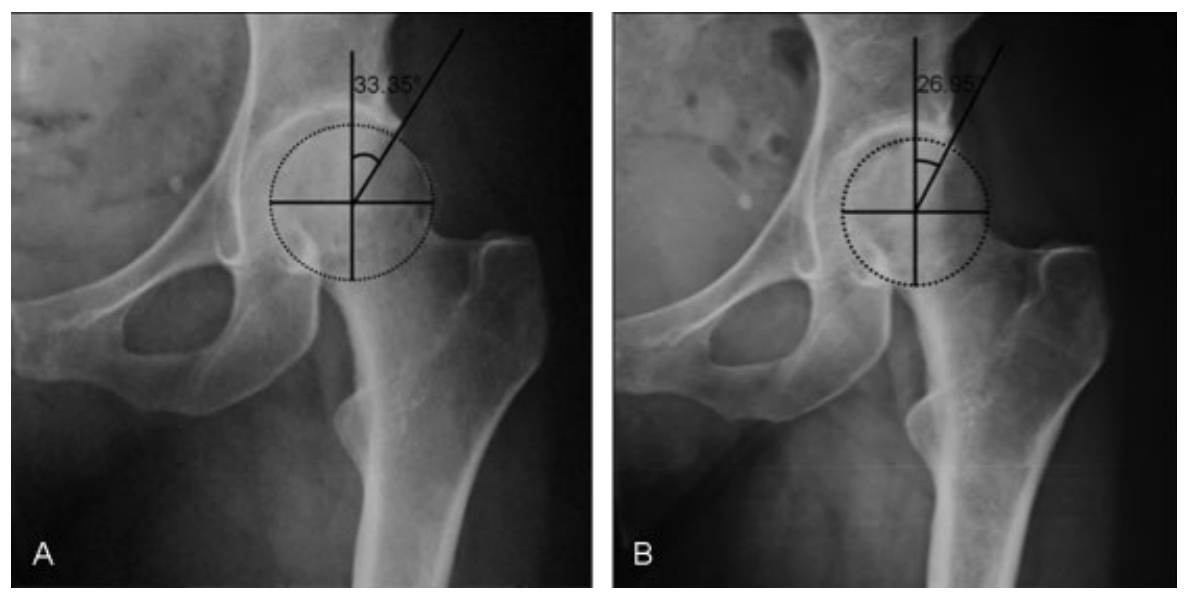

Fig. 1 Standard anteroposterior view of a 36-year-old female patient presenting without persistent hip pain at follow-up. Center-edge angle measured 33.35 degrees preoperatively (A) and 26.95 degrees postoperatively (B). 

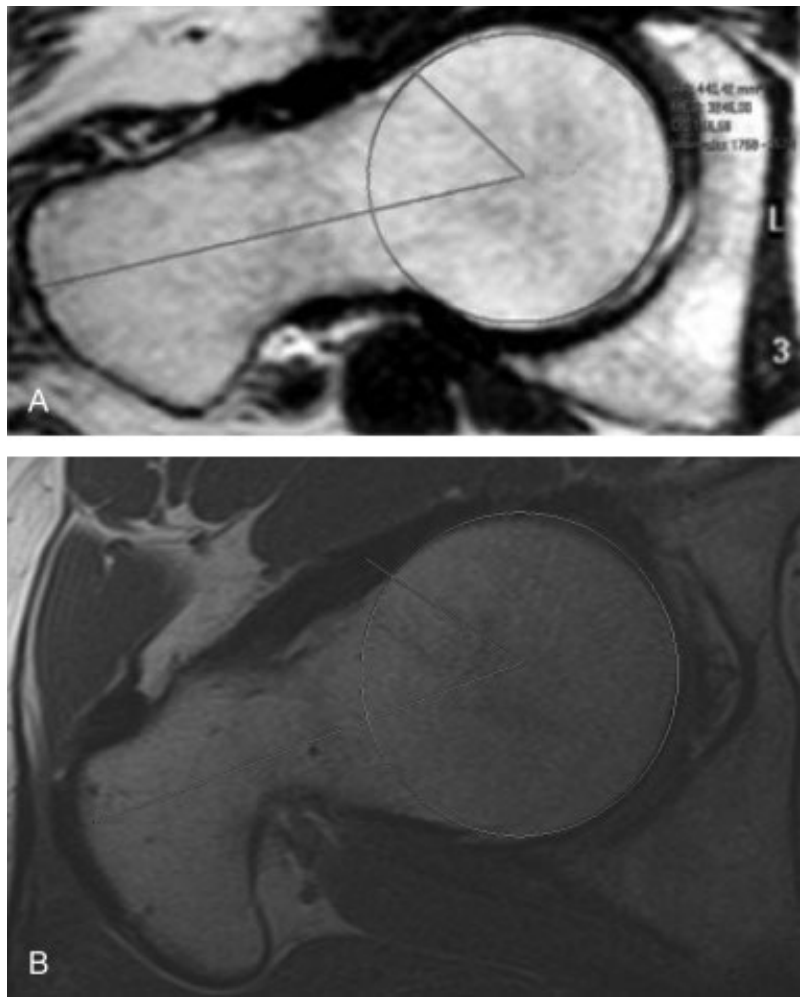

Fig. 2 Axial magnetic resonance imaging views of the same patient reported in - Fig. 1 showing reduction of the $\alpha$ angle after surgery from 63.2 degrees preoperatively (A) to 54.3 degrees postoperatively (B).

authors $^{38,39}$ questioned its ability to improve the diagnosis of cam-type FAI.

There is an increasing evidence that an insufficient correction of femoral and acetabular bony abnormalities is a cause of persistent groin pain and poor postoperative outcomes. $^{7,9,11,15,16}$ On the other hand, an excessive correction of these deformities may lead to femoral neck fracture and hip instability. ${ }^{40,41}$ In patients in whom the correction of the $\alpha$ angle to less than 55 degrees would lead to excessive resection, limiting reduction by no more than 20 degrees should be considered. ${ }^{42}$

de Sa et al ${ }^{15}$ included a total of 14 studies ( 12 case series, 1 prospective cohort study, and 1 case-control study) in their systematic review and meta-analysis, with a follow-up between 1 and 4 years. Thirteen of these studies reported a postoperative $\alpha$ angle less or equal to 55 degrees. Only one of these studies ${ }^{13}$ was a prospective ongoing study on 106 patients (118 hips) treated with a minimally -invasive anterolateral approach, at an average follow-up of 2.2 years. The authors reported a significant improvement on the mean $\alpha$ angle from 61.8 to 36.9 degrees, with a significant improvement in all range of motions after surgical correction of the $\alpha$ angle to less than 55 degrees. ${ }^{13}$

Other papers, not included in the aforementioned review, reported on postoperative imaging in FAI. ${ }^{11,12,14}$ Philippon et $\mathrm{al}^{11}$ in their prospective study reported on 58 hips a mean reduction of CE angle of 3.9 (range: 0 - 17) degrees. They showed that change in CE angle could be estimated from millimeters of acetabular bony resection, and the $\mathrm{CE}$ angle is a reliable radiographic diagnostic tool for the measurement of acetabular coverage. Bedi et al, ${ }^{12}$ in their prospective nonrandomized study on 60 male patients younger than 40 years treated with either an arthroscopic or an open approach, reported that the imaging results of arthroscopic osteochondroplasty were comparable to open surgical dislocation for anterior and anterosuperior cam and focal rim impingement deformity. However, the authors reported that open technique resulted in greater correction of posterosuperior loss of femoral offset and may be favorable for FAI patterns that demonstrate considerable proximal femoral deformity on AP radiographs. Zingg et al, ${ }^{14}$ in their prospective comparative study on 28 patients treated with either an open or arthroscopic approach, at 6 weeks follow-up, reported on MRI that arthroscopic osteochondroplasty removed more bone than necessary in some positions, resulting in significant lower $\alpha$ angles. The authors complained that this overcorrection is unwelcomed since irreversible and may be an issue in terms of joint sealing. We
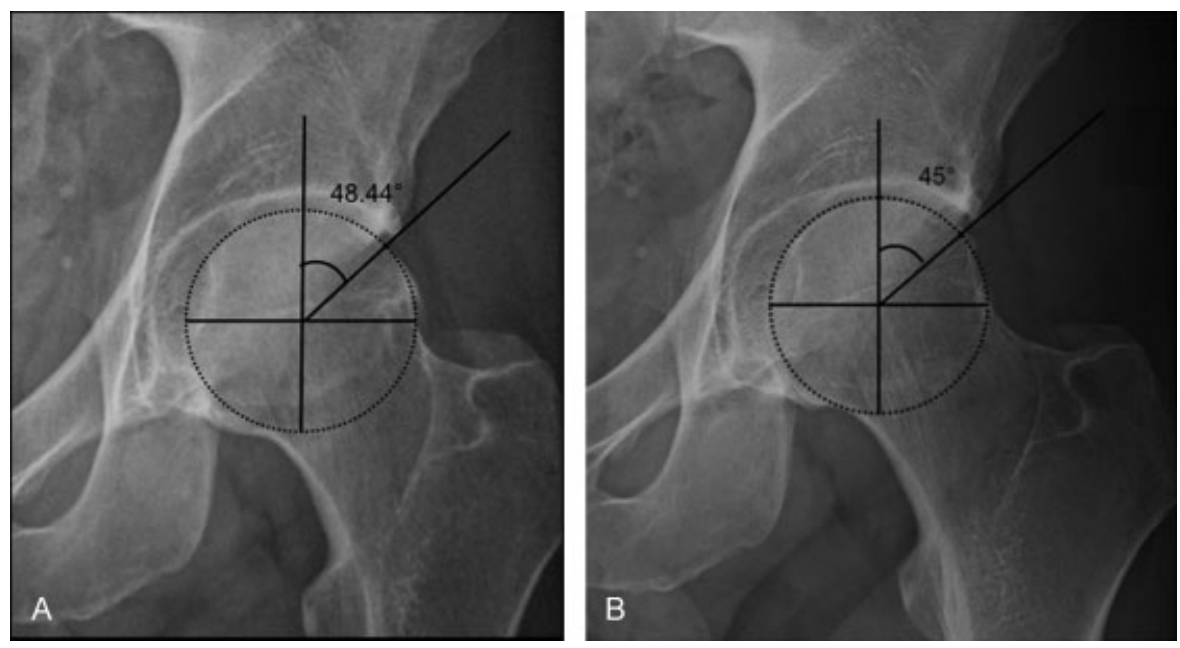

Fig. 3 Standard anteroposterior view of a 36-year-old male patient presenting with persistent hip pain at follow-up. Center-edge angle measured 48.44 degrees preoperatively (A) and 45 degrees postoperatively (B). 

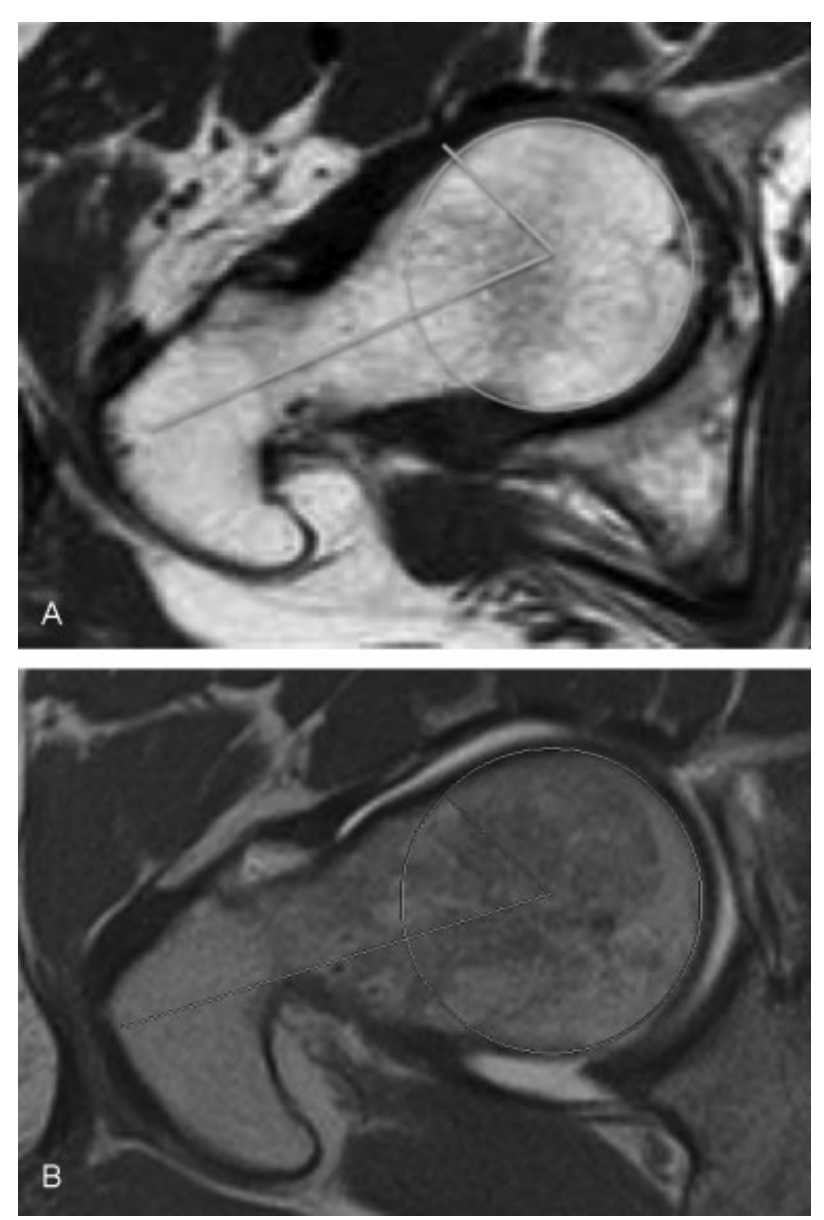

Fig. 4 Magnetic resonance imaging scans of the same patient reported in - Fig. 3 showing an insufficient reduction of the $\alpha$ angle after surgery from degrees 71.5 preoperatively (A) to 60.9 degrees postoperatively (B).

think that the results of this study should be taken with caution; in fact, most of the scrutinized patients refused to be included into the study, and most of the enrolled patients were not randomized.

In our study, mean values of all the analyzed radiological parameters improved significantly after surgery, except mean CE angle in patients with residual hip pain $(p=0.1)$. On comparing the two subgroups, significant lower postoperative $\alpha$ angles were observed in patients without pain $(p=0.008)$. CE angle was lower in patients without pain, albeit difference did not reach statistical significance $(p=0.07)$.

This study has some strengths. Patients were selected according to strict inclusion and exclusion criteria, and a homogeneous group of mixed-type FAI patients was analyzed. Imaging studies were acquired with the same standardized protocol and analyzed by the same welltrained musculoskeletal radiologist in a blinded fashion. Radiological parameters were considered both on the femur and the acetabulum.

Several limitations have to be recognized. Certainly, this is a retrospective study with a small sample size; results are reported at a short-term follow-up, still in the range of previously reported literature (6 weeks to 45 months). ${ }^{10-15}$ Finally, preoperative and postoperative functional scores were not reported, but this was beyond this study.

In conclusion, in case of persistent pain after arthroscopic treatment of FAI, a set of imaging studies should be performed. The recognition of the anatomical changes following arthroscopic treatment is an important step to avoid a wrong clinical evaluation after therapy. Persistent pain after arthroscopic treatment of FAI may be due to an insufficient correction of preoperative radiological abnormalities.

\section{References}

1 Baker JF, Mulhall KJ. Femoro-acetabular impingement and hip pain with conventionally normal X-rays. Ir Med J 2010;103(06): 184-186

2 Beck M, Kalhor M, Leunig M, Ganz R. Hip morphology influences the pattern of damage to the acetabular cartilage: femoroacetabular impingement as a cause of early osteoarthritis of the hip. J Bone Joint Surg Br 2005;87(07):1012-1018

3 Sink EL, Gralla J, Ryba A, Dayton M. Clinical presentation of femoroacetabular impingement in adolescents. J Pediatr Orthop 2008;28(08):806-811

4 Botser IB, Smith TW Jr, Nasser R, Domb BG. Open surgical dislocation versus arthroscopy for femoroacetabular impingement: a comparison of clinical outcomes. Arthroscopy 2011; 27(02):270-278

5 Griffiths EJ, Khanduja V. Hip arthroscopy: evolution, current practice and future developments. Int Orthop 2012;36(06): 1115-1121

6 Imam S, Khanduja V. Current concepts in the diagnosis and management of femoroacetabular impingement. Int Orthop 2011;35(10):1427-1435

7 Philippon MJ, Schenker ML, Briggs KK, Kuppersmith DA, Maxwell RB, Stubbs AJ. Revision hip arthroscopy. Am J Sports Med 2007; 35(11):1918-1921

8 Aprato A, Jayasekera N, Villar RN. Revision hip arthroscopic surgery: outcome at three years. Knee Surg Sports Traumatol Arthrosc 2014;22(04):932-937

9 Heyworth BE, Shindle MK, Voos JE, Rudzki JR, Kelly BT. Radiologic and intraoperative findings in revision hip arthroscopy. Arthroscopy 2007;23(12):1295-1302

10 Larson CM, Giveans MR. Arthroscopic management of femoroacetabular impingement: early outcomes measures. Arthroscopy 2008;24(05):540-546

11 Philippon MJ, Wolff AB, Briggs KK, Zehms CT, Kuppersmith DA. Acetabular rim reduction for the treatment of femoroacetabular impingement correlates with preoperative and postoperative center-edge angle. Arthroscopy 2010;26(06):757-761

12 Bedi A, Zaltz I, De La Torre K, Kelly BT. Radiographic comparison of surgical hip dislocation and hip arthroscopy for treatment of cam deformity in femoroacetabular impingement. Am J Sports Med 2011;39(Suppl):20S-28S

13 Chiron P, Espié A, Reina N, Cavaignac E, Molinier F, Laffosse JM. Surgery for femoroacetabular impingement using a minimally invasive anterolateral approach: analysis of 118 cases at 2.2-year follow-up. Orthop Traumatol Surg Res 2012;98(01):30-38

14 Zingg PO, Ulbrich EJ, Buehler TC, Kalberer F, Poutawera VR, Dora C. Surgical hip dislocation versus hip arthroscopy for femoroacetabular impingement: clinical and morphological short-term results. Arch Orthop Trauma Surg 2013;133(01):69-79

15 de Sa D, Urquhart N, Philippon M, Ye JE, Simunovic N, Ayeni OR. Alpha angle correction in femoroacetabular impingement. Knee Surg Sports Traumatol Arthrosc 2014;22(04):812-821 
16 Dietrich TJ, Dora C, Pfirrmann CW. Postoperative imaging in femoroacetabular impingement. Semin Musculoskelet Radiol 2013;17(03):272-278

17 Ganz R, Parvizi J, Beck M, Leunig M, Nötzli H, Siebenrock KA. Femoroacetabular impingement: a cause for osteoarthritis of the hip. Clin Orthop Relat Res 2003;(417):112-120

18 Nötzli HP, Wyss TF, Stoecklin CH, Schmid MR, Treiber K, Hodler J. The contour of the femoral head-neck junction as a predictor for the risk of anterior impingement. J Bone Joint Surg Br 2002; 84(04):556-560

19 Reynolds D, Lucas J, Klaue K. Retroversion of the acetabulum. A cause of hip pain. J Bone Joint Surg Br 1999;81(02):281-288

20 Ruelle M, Dubois JL. The protrusive malformation and its arthrosic complication. I. Radiological and clinical symptoms. Etiopathogenesis [in French]. Rev Rhum Mal Osteoartic 1962;29:476-489

21 Van De Velde S, Fillman R, Yandow S. The aetiology of protrusio acetabuli. Literature review from 1824 to 2006. Acta Orthop Belg 2006;72(05):524-529

22 Aprato A, Jayasekera N, Villar R. Timing in hip arthroscopy: does surgical timing change clinical results? Int Orthop 2012;36(11): 2231-2234

23 Wiberg G. Studies on dysplastic acetabula and congenital subluxation of the hip joint: with special reference to the complication of osteoarthritis. Acta Chir Scand Suppl 1939;58:7-135

24 Tönnis D, Heinecke A. Acetabular and femoral anteversion: relationship with osteoarthritis of the hip. J Bone Joint Surg Am 1999;81(12):1747-1770

25 Siebenrock KA, Kalbermatten DF, Ganz R. Effect of pelvic tilt on acetabular retroversion: a study of pelves from cadavers. Clin Orthop Relat Res 2003;(407):241-248

26 Aprato A, Jayasekera N, Villar RN. The accuracy of magnetic resonance arthrography in hip arthroscopic labral revision surgery. Hip Int 2013;23(01):99-103

27 Beaulé PE, Zaragoza E, Motamedi K, Copelan N, Dorey FJ. Threedimensional computed tomography of the hip in the assessment of femoroacetabular impingement. J Orthop Res 2005;23(06): 1286-1292

28 Locher S, Werlen S, Leunig M, Ganz R. MR-Arthrography with radial sequences for visualization of early hip pathology not visible on plain radiographs [in German]. Z Orthop Ihre Grenzgeb 2002;140(01):52-57

29 Siebenrock KA, Wahab KH, Werlen S, Kalhor M, Leunig M, Ganz R. Abnormal extension of the femoral head epiphysis as a cause of cam impingement. Clin Orthop Relat Res 2004;(418):54-60
30 Pfirrmann CW, Mengiardi B, Dora C, Kalberer F, Zanetti M, Hodler J. Cam and pincer femoroacetabular impingement: characteristic MR arthrographic findings in 50 patients. Radiology 2006;240(03):778-785

31 Steppacher SD, Tannast M, Werlen S, Siebenrock KA. Femoral morphology differs between deficient and excessive acetabular coverage. Clin Orthop Relat Res 2008;466(04):782-790

32 Dudda M, Albers C, Mamisch TC, Werlen S, Beck M. Do normal radiographs exclude asphericity of the femoral head-neck junction? Clin Orthop Relat Res 2009;467(03):651-659

33 Pozzi G, Stradiotti P, Parra CG, Zagra L, Sironi S, Zerbi A. Femoroacetabular impingement: can indirect MR arthrography be considered a valid method to detect endoarticular damage? A preliminary study. Hip Int 2009;19(04):386-391

34 Mintz DN, Hooper T, Connell D, Buly R, Padgett DE, Potter HG. Magnetic resonance imaging of the hip: detection of labral and chondral abnormalities using noncontrast imaging. Arthroscopy 2005;21(04):385-393

35 Armfield DR, Towers JD, Robertson DD. Clinical evaluation of the hip: radiologic evaluation. Oper Tech Orthop 2005;15:182-190

36 Tsitskaris K, Sharif K, Meacock LM, et al. The prevalence of camtype femoroacetabular morphology in young adults and its effect on functional hip scores. Hip Int 2012;22(01):68-74

37 Meyer DC, Beck M, Ellis T, Ganz R, Leunig M. Comparison of six radiographic projections to assess femoral head/neck asphericity. Clin Orthop Relat Res 2006;445(445):181-185

38 Lohan DG, Seeger LL, Motamedi K, Hame S, Sayre J. Cam-type femoral-acetabular impingement: is the alpha angle the best MR arthrography has to offer? Skeletal Radiol 2009;38(09):855-862

39 Nouh MR, Schweitzer ME, Rybak L, Cohen J. Femoroacetabular impingement: can the alpha angle be estimated? AJR Am J Roentgenol 2008;190(05):1260-1262

40 Rothenfluh E, Zingg P, Dora C, Snedeker JG, Favre P. Influence of resection geometry on fracture risk in the treatment of femoroacetabular impingement: a finite element study. Am J Sports Med 2012;40(09):2002-2008

41 Mardones RM, Gonzalez C, Chen Q, Zobitz M, Kaufman KR, Trousdale RT. Surgical treatment of femoroacetabular impingement: evaluation of the effect of the size of the resection. J Bone Joint Surg Am 2005;87(02):273-279

42 Brunner A, Horisberger M, Herzog RF. Evaluation of a computed tomography-based navigation system prototype for hip arthroscopy in the treatment of femoroacetabular cam impingement. Arthroscopy 2009;25(04):382-391 